\title{
A rarely seen lipoma variant: Osteochondrolipoma: Case report
}

\author{
Ender görülen bir lipom varyantı: Osteokondrolipom: Olgu sunumu
}

\author{
Ayşe Bahar CEYRAN ${ }^{1}$, Murat DEMIROĞLU², Serkan ŞENOL ${ }^{1}$, Bengü ÇOBANOĞLU ŞiMŞEK ${ }^{1}$, Korhan ÖZKAN ${ }^{2}$
}

\begin{abstract}
Lipomas which are the most common tumors of the soft tissue can be often accompanied by fibrous tissue, blood vessels, smooth muscle, myxoid areas; and they rarely contain bone marrow, chondroid nodules and bone formation areas. Lipomas containing both bony and chondroid areas are extremely rare and have been reported most commonly in head, neck and intraoral areas. A 54 year- old female patient had a $7 \mathrm{~cm}$-long subcutaneous mass in the forearm which was discovered five years ago. USG and $M R$ findings had indicated lipoma. Radiologic examinations performed due to recently hardened painful mass revealed an atypical lipoma raising the suspicion of low grade liposarcoms. As the spindle-cell areas in the fatty tissue were seen in the trucut biopsy material , total excision was applied for differential diagnosis. Histopathological examination of the material, the lesion was reported as osteochondrolipoma. Osteochondrolipomas have been accepted as a variant of conventional lipomas as a result of the cytogenetic studies. It might be difficult to diagnose this very rarely seen osteochondrolipomas in the tru-cut or small biopsy specimens. Both clinically, radiologically and histopathologically differential diagnosis might be difficult. This case is the 6th OCL case which has been reported in the literature so far, and the first case in the forearm area.
\end{abstract}

Keywords: Osteochondroma, lipoma, variant öz

Yumuşak dokunun en sık tümörü olan lipomlara, sıklıkla fibröz bağ dokusu, kan damarları, düz kas, miksoid alanlar eşlik edebilir. Lipomlar, ender olarak da kemik iliği, kıkırdak nodülleri ve kemik formasyon alanları içerebilir. Hem kemik hem de kıkırdak alanlarını içeren lipomlar ise son derece ender olup, daha çok baş boyun bölgesinde ve ağız içinde bildirilmiştir. Elli dört yaşında bir kadın hastada, 5 yıl önce, ön kol cilt altında fark edilen, USG ve MR bulguları lipom ile uyumlu $7 \mathrm{~cm}$ çaptaki kitle mevcuttur. Kitlenin son zamanlarda sertleşerek ağrı yapmaya başlaması üzerine yapılan radyolojik incelemelerde atipik lipom-düşük dereceli liposarkom şüphesi saptanmıştır. Bu nedenle yapılan tru cut biyopsi materyalinde izlenen yağ doku alanları içindeki iğsi hücreli alanlar nedeniyle kesin ayırıcı tanı için total eksizyon uygulanmıştır. Materyalin histopatolojik incelemesinde lezyon, osteokondrolipom olarak rapor edilmiştir. Yapılan sitogenetik çalışmalar ile konvansiyonel lipomların varyantı olarak kabul edilen ve son derece ender görülen osteokondrolipomları, tru-cut veya küçük biyopsi materyallerinde değerlendirmek zor olabilir. Hem klinik, radyolojik hem de histopatolojik olarak ayırıcı tanıda güçlük oluşturabilirler. Olgumuz şimdiye kadar bildirilmiş altıncı OKL olgusu olup ön kol lokalizasyonunda bildirilen ilk olgu olma özelliğini göstermektedir.

Anahtar kelimeler: Osteokondrom, lipom, varyant

\section{Giriş}

Lipomlar, en sık görülen yumuşak doku tümörüdür. Kırk-altmış yaş aralığında ve erkeklerde daha sıktır. Yüzeyel, derin ve hatta kemik yüzeylerinde (parosteal) yerleşim gösterebilirler.

Lipomlara başta fibröz bağ dokusu (fibrolipom) olmak üzere, kan damarları (anjiolipom), düz kas (myolipom), miksoid alanlar (miksolipom), ender olarak kemik iliği (myelolipom), kıkırdak nodülleri (kondrolipom) ve kemik formasyon alanları (osteolipom) eşlik edebilir. Bu mikroskopik alt tiplerin klinik bir önemi yoktur ${ }^{1,2}$.

Kıkırdak ve kemik oluşumlarını bir arada içeren lipomlar ise son derece ender olup, daha çok baş boyun bölgesinde ve ağız içinde bildirilmiştir ${ }^{3}$. Bu olgular osteo/kondrolipom, kartilagenöz/osseöz değişiklik gösteren lipom gibi değişik şekillerde isimlendirilmişlerdir. Osseöz ve kondroid differansiyasyon etyolojilerinin belirsizliği bu isim karmaşasına neden olmuştur.

Received: 28.11.2015

Accepted: 11.01 .2016

${ }^{1}$ Department of Pathology, Istanbul Medeniyet University, Göztepe Training and Research Hospital

${ }^{2}$ Department of Orthopedics, Istanbul Medeniyet University, Göztepe Training and Research Hospital

Yazışma adresi: Ayşe Bahar Ceyran, Department of Pathology, Istanbul Medeniyet University, Göztepe Training and Research Hospital, İstanbul e-mail: baharceyran@gmail.com 
Biz ön kolda, yüzeyel (subkutan) yerleşimli bir osteokondrolipom (OKL) olgusunu sunuyoruz. Literatürde şimdiye kadar bildirilmiş, 10 kadar OKL olgusu vardır. Bizim olgumuz ise bu lokalizasyonda bildirilmiş ilk olgu özelliğini taşımaktadır. Ender görülmesi nedeniyle ve ayırıcı tanıda güçlük oluşturabileceğini düşünerek olgumuzu sunmayı amaçladık.

\section{OLGU SUNUMU}

Elli dört yaşında kadın hastada, sol ön kol cilt altında 5 yıl önce fark edilen, yavaş büyüyen, ağrısız yumuşak doku kitlesi mevcuttur. İlk yapılan USG ve MR incelemelerinde lipom ile uyumlu $7 \mathrm{~cm}$ çaplı kitle rapor edilerek takibi planlanmıştır. Son zamanlarda sertleşerek ağrı yapmaya başlaması üzerine yapılan direkt grafi (Figür 1) ve MR incelemelerinde atipik lipomdüşük dereceli liposarkom düşündürmüştür. Kitleden tru-cut biyopsi yapılarak histopatolojik incelemeye gönderilmiştir.

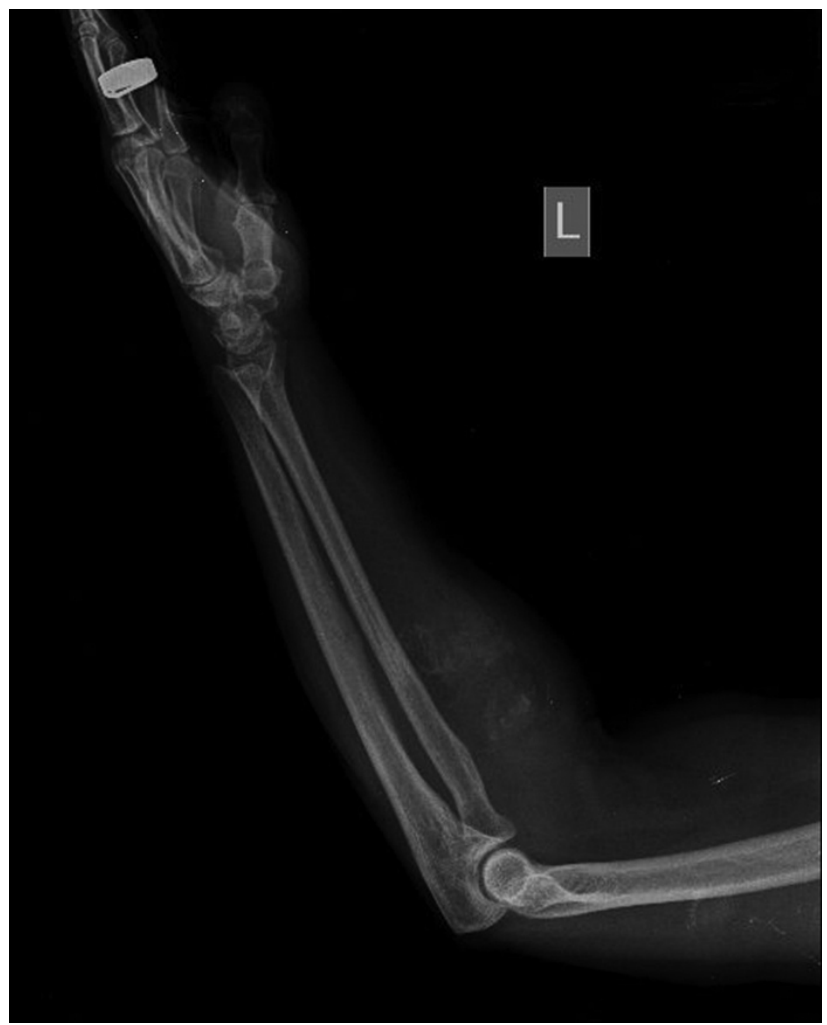

Figür 1. Sol ön koldaki kitlenin direk grafideki görünümü.

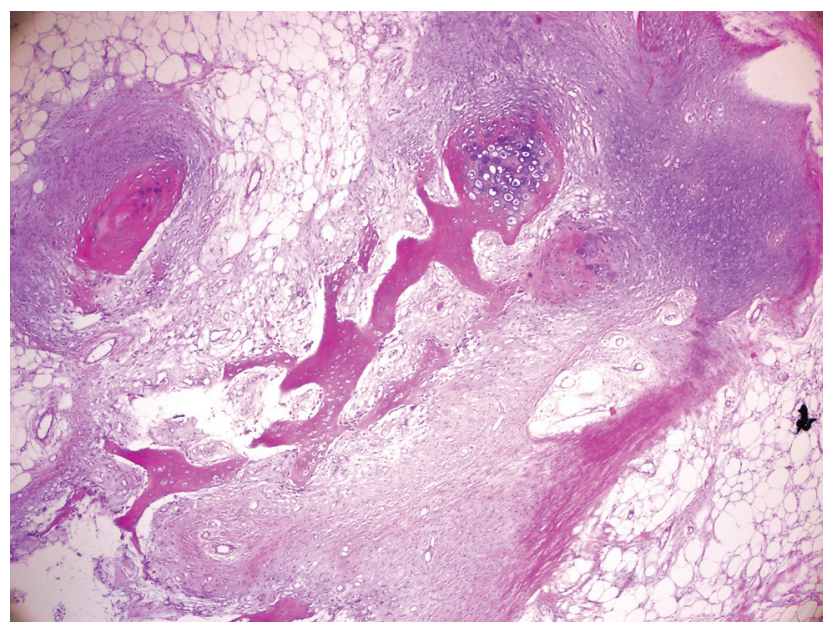

Figür 2. Yağ doku içindeki iğsi hücreli migzoid alanlar arasında kıkırdaktan yeni kemik oluşumu alanları, H\&E. x40.

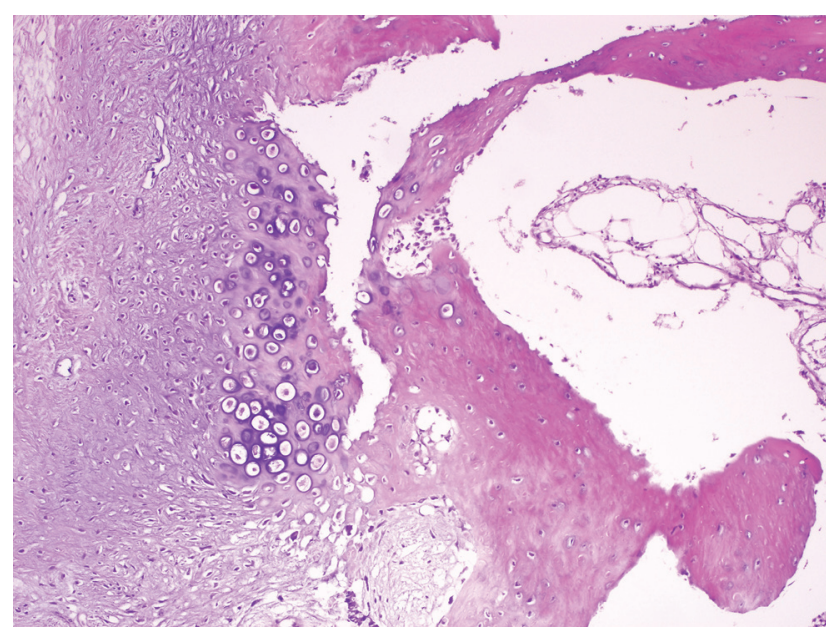

Figür 3. Kıkırdaktan yeni kemik oluşumu ve sol yanda hafif sellüler görünümlü iğsi hücreli alanlar, H\&E. x100.

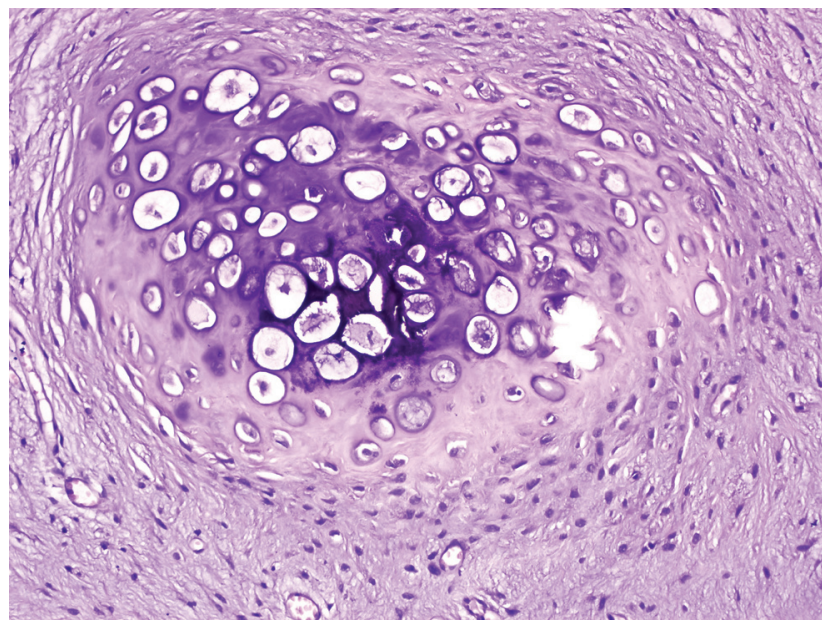

Figür 4. İğsi hücreli, hafif sellüler alan ortasında osteokartilagenöz differansiyasyon odağı, H\&E. x200. 


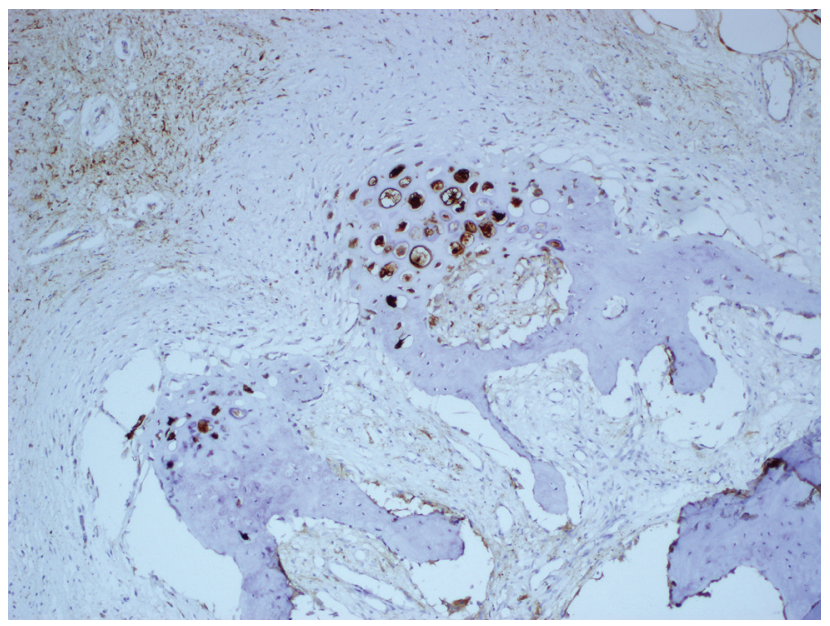

Figür 5. İmmünohistokimyasal S 100 boyamasında kıkırdak doku lobulleri ve yağ dokuda pozitif boyanma, x100.

Histopatolojik incelemede, yağ dokusu içinde iğsi hücreli alanlar tanımlanarak malignitenin kesin olarak ekarte edilebilmesi için kitlenin total eksizyonu önerilmiştir.

Total eksizyon materyalinin histopatolojik incelemesinde, yaygın matür yağ hücre lobullerinden meydana gelen tümöral yapı içinde düzenli, matür kemik doku lamelleri ve hiyalin kıkırdak doku alanları ile arada enkondral ossifikasyon alanları izlenmiştir (Figür 2). Kemik ve kıkırdak doku alanları çevresinde ise yer yer miksoid özellikte, genellikle hiposellüler, yer yer hafif sellüler, iğsi hücreli alanlar dikkati çekmiştir (Figür 3-4). Sitolojik atipi, mitoz, nekroz izlenmemiştir. İmmünohistokimyasal incelemelerde, yağ doku ve kıkırdak doku alanlarında S 100 ile pozitif boyanma (Figür 5) izlenmiş olup, Ki 67 proliferasyon indeksi \%1'den az bulunmuştur. Bu bulgular ile lezyon "osteokondrolipom" olarak rapor edilmiştir.

\section{TARTIŞMA}

Klasik olarak lipomlar matür yağ hücre lobullerinden oluşur. Yüzeyel, derin veya kemik yüzeylerinde (parosteal) oluşabilir ${ }^{4}$. İntraosseöz lipomlar kemiğin içinde olur. Osteolipom veya ossifying lipom, alttaki kemik ile ilişkisiz olan yumuşak doku içindeki, matür kemik alanları içeren lipomlar için kullanılır. Alttaki kemiğin periostu ile ilişkili olanlar için ossifying parosteal lipom terimi genellikle tercih edilir ${ }^{3}$.
Lipomda kemik differansiyasyonu nadirdir. Osteolipom olgularının \%60'tan çoğu baş-boyun bölgesinde olup, intraspinal, intrakranial, ekstrakranialekstraspinal, çoğunlukla da intraoral lokalizasyonlarda bildirilmiştir ${ }^{3,5-7}$. Baş-boyun bölgesi dışında kemik dokuya yakın derin bölgelerde, uyluk, diz, omuz, el bileği ve elde, veya yüzeyel subkutan dokuda bildirilmiş olgular vardır ${ }^{8-13}$.

Hem kemik hem de kıkırdak differansiyasyonu gösteren lipomlar ise son derece ender görülür. 19602015 yılları arasındaki İngilizce literatürde bildirilmiş toplam 10 kadar osteokondroid differansiyasyonlu lipom olgusu vardır ${ }^{3,9,14-21}$. Bunlar submandibuler, alt dudak girişi, göğüs duvarı, intrapatellar tendon, uyluk, mandibula, poplitea, skapula, intratentorial ve kalça lokalizasyonludur, ${ }^{3,9,14-21}$. Olgumuz ise ön kolda, subkutan (yüzeyel) yerleşimlidir. Bu lokalizasyonda ilk olma özelliğine sahiptir.

Birçok tümörde olduğu gibi lipomların etyolojisi de belirsizdir. Kronik iritasyon, travma ve spontan gelişim öne sürülür. Lipomlarda görülen kemik ve kıkırdak doku alanlarının etiyolojisi ise tartışmalıdır ve bunların undifferansiye mezanşimal hücrelerin değişik tiplerinden kaynaklandığı ileri sürülür ${ }^{15}$. Bu lezyonların patogenezi ile ilgili iki ana teori vardır. Birincisi, bu tümörler, yağ doku kökenli kök hücrelerin doğrudan doğruya değişik dokulara differansiye olmalarından kaynaklanır. İkincisine göre ise, fibroblastların tekrarlayan travma, metabolik değişiklikler veya iskemi gibi nedenlerle sekonder metaplazi göstermeleri ile açıklanır ${ }^{3,11,22,23}$.

Osteolipom ve parosteal lipomlar üzerinde yapılan bazı sitogenetik çalışmalar, bunların klasik yumuşak doku lipomları ile aynı t $(3 ; 12)$ translokasyonlarına sahip olduklarını göstermiştir ${ }^{9,11,24-26}$. Matsui ve ark. ${ }^{9}$ bir tendon lipomunun hem fibro-adipöz hem de kondro-osseöz komponentlerinin aynı HMGA2-LPP füsyon transkriptini gösterdiklerini saptamışlardır. Bu durum, HMGA2-LPP füzyon proteininin, hem fibroadipogenezi hem de osteokondrogenezi uyardığını düşündürür. Tüm bu çalışmalar, bu tümörlerin konvansiyonel lipomun varyantları olduğunu destekler. 
Bu tür lipomlar, lokalizasyonu ne olursa olsun, benign adipositik neoplazmlardır ve tam eksizyondan sonra genellikle nüks göstermezler ${ }^{3}$.

Osteokondrolipomların ayırıcı tanısına birçok mezanşimal lezyonlar girer. Bunlardan mezanşimal hamartomlar hemen daima neonatal ve çocukluk döneminde görülür. Çok büyük ve kısmen kistik olabilirler. Mikroskopik olarak lezyonun hamartomatöz karakteri, matür elemanların düzensiz karışımından anlaşılır. Fibröz doku, yağ doku, damar boşlukları, düz kas, sinirler, kıkırdak ve sıklıkla hematopoetik kemik iliği bulunan kemik trabekülleri içerirler. Osteokondrolipomlarda ise yağ, bağ, kıkırdak ve kemik oluşumları genellikle düzgün ve keskin sınırlı odaklar oluştururlar ve asıl tümöral komponent matür yağ dokusudur.

Ayırıcı tanıya giren diğer tümörlerden, teratom, ossifying fibrom, miyozitis ossifikans ve extraskeletal osteokondromlarda da asıl tümöral komponent yağ doku değildir.

Düşük dereceli fibromiksoid sarkom ve miksofibrosarkomun kesin ayırımı için her zaman geniş eksizyon materyalinde bütünüyle değerlendirme yapabilmek önemlidir. Tru-cut veya küçük biyopsi materyallerinde bu lezyonları değerlendirmek zor olabilir.

Bizim olgumuzda da lezyona önce tru-cut biyopsi yapılmış ve biyopside kondromiksoid, yer yer hipersellüler alanlar izlenmesi nedeniyle, kondromiksoid özellik gösterebilen benign ve malign lezyonlar ekarte edilememiştir. Olguya total eksizyon materyalinde "osteokondrolipom" kesin tanısı verilebilmiştir.

Bu lezyonlar bazen klinik bulgular ve radyolojik olarak da malignite ile karışabilir. Klinikte sert oluşu, bazen ani büyüme göstermesi, radyolojik olarak kemik ve kıkırdak alanları içermesi buna neden olabilir. Ancak, radyolojik olarak çoğunlukla yağ dokudan oluşması benign lipomatöz lezyon lehine değerlendirilebilir.

Sonuç olarak, osteokondrolipomlar son derece ender görülen lezyonlardır. Hem klinik, radyolojik hem de histopatolojik olarak ayırıcı tanıda güçlük oluşturabi- lirler. Olgumuz şimdiye kadar ön kol lokalizasyonunda bildirilen ilk olgu olma özelliğini göstermektedir.

\section{KAYNAKLAR}

1. Weiss SW, Goldblum JR. Enzinger and Weiss's Soft Tissue Tumors, $5^{\text {th }}$ Edition, Mosby Elsevier, 2008, pp:431-452.

2. Fisher C, Montgomery EA, Thway K. Biopsy Interpretation of Soft Tissue Tumors. Lippincott Williams \& Wilkins, 2011, pp:343-359.

3. Soulard R, Nguyen AT, Souraud JB, et al. Osteochondrolipoma of the submandibular region: a case report and review of the literature. Head Neck Pathol 2012;6(4):486-491. http://dx.doi.org/10.1007/s12105-012-0358-3

4. Fletcher CD, Bridge JA, Hogendorn PC, Mertens F. Who Classification of Tumours of Soft Tissue and Bone, $4^{\text {th }}$ Edition, Lyon, 2013, pp:20-21.

5. Jaiswal AK, Garg A, Mahapatra AK. Spinal ossifying lipoma. J Clin Neurosci 2005;12(6):714-721. http://dx.doi.org/10.1016/j.jocn.2004.08.031

6. Lin YC, Huang CC, Chen HJ. Intraspinal osteolipoma. Case report. J Neurosurg 2001;94(1 Suppl):126-134.

7. Park YS, Kwon JT, Park US. Interhemispheric osteolipoma with agenesis of the corpus callosum. J Korean Neurosurg Soc 2010;47(2):148-150. http://dx.doi.org/10.3340/jkns.2010.47.2.148

8. Jamshidi K, Qomashi I, Shirazi MR. An unusual location of ossified intramuscular lipoma: a case report. Acta Med Iran 2011;49(9):630-632.

9. Matsui $Y$, Hasegawa $T$, Kubo $T$, et al. Intrapatellar tendon lipoma with chondro-osseous differentiation: detection of HMGA2-LPP fusion gene transcript. J Clin Pathol 2006;59(4):434-440. http://dx.doi.org/10.1136/jcp.2005.026393

10. Obermann EC, Bele S, Brawanski A, et al. Ossifying lipoma. Virchows Arch 1999;434(2):181-184. http://dx.doi.org/10.1007/s004280050324

11. Fritchie KJ, Renner JB, Rao KW, Esther RJ. Osteolipoma: radiological, pathological, and cytogenetic analysis of three cases. Skeletal Radiol 2012;41(2):237-244. http://dx.doi.org/10.1007/s00256-011-1241-0

12. Teoh LC, Chan LK, Lai SH. Ossifying lipoma of the hand: a case report. Ann Acad Med Singapore 2001;30(5):536-544.

13. Val-Bernal JF, Val D, Garijo MF, et al. Subcutaneous ossifying lipoma: case report and review of the literature. J Cutan Pathol 2007;34(10):788-792.

http://dx.doi.org/10.1111/j.1600-0560.2006.00704.x

14. Hoch B, Hermann G, Klein MJ, Abdelwahab IF. Ossifying chondroid lipoma. Skeletal Radiol 2008;37(5):475-480. http://dx.doi.org/10.1007/s00256-007-0444-x

15. Kuyama K, Fifita SF, Komiya M, et al. Rare Lipomatous Tumors with Osseous and/or Chondroid Differentiation in the Oral Cavity Report of Two Cases and Review of the Literature. Int J Dent 2009; 2009: 143460. Published online 2009 Nov 4.

16. Gru AA, Santa Cruz DJ. Osteochondrolipoma: a subcutaneous lipoma with chondroid and bone differentiation of the chest wall. J Cutan Pathol 2012;39(4):461-464. http://dx.doi.org/10.1111/j.1600-0560.2011.01855.x

17. Gültekin SE, Kahraman S, Karadayı K. Parosteal osteochondrolipoma of the mandible. J Oral Maxillofac Pathol 2012;16(2):280-2. http://dx.doi.org/10.4103/0973-029X.99090 
18. Choi YJ, Kang JH, Kang GH, Choi SJ. Osteochondrolipoma Presenting as a Popliteal Cyst. Clin Orthop Surg 2015;7(2):264-8.

http://dx.doi.org/10.4055/cios.2015.7.2.264

19. Nishio J, Ideta S, Iwasaki H, Naito M. Scapular osteochondrolipoma: Imaging features with pathological correlation. Oncol Lett 2013;6(3):817-820. Epub 2013 Jul 11.

http://dx.doi.org/10.3892/ol.2013.1455

20. Ahmadi SA, van Landeghem FK, Blechschmidt C, et al. Intratentorial osteochondrolipoma in a 9-year-old boy. J Neurosurg Pediatr 2009;3(5):386-91.

http://dx.doi.org/10.3171/2009.1.PEDS08237

21. Rau T, Soeder S, Olk A, Aigner T. Parosteal lipoma of the thigh with cartilaginous and osseous differentiation: an osteochondrolipoma. Ann Diagn Pathol 2006;10(5):279-82. http://dx.doi.org/10.1016/j.anndiagpath.2006.03.009

22. Piattelli A, Fioroni M, lezzi G, Rubini C. Osteolipoma of the tongue. Oral Oncol 2001;37(5):468-470.

http://dx.doi.org/10.1016/S1368-8375(00)00105-6
23. Demiralp B, Alderete JF, Kose O, et al. Osteolipoma independent of bone tissue: a case report. Cases J 2009;2:8711. http://dx.doi.org/10.4076/1757-1626-2-8711

24. Bridge JA, DeBoer J, Walker CW, Neff JR. Translocation t(3;12) (q28;q14) in parosteal lipoma. Genes Chromosomes Cancer 1995;12(1):70-72. http://dx.doi.org/10.1002/gcc.2870120113

25. Petit MM, Swarts S, Bridge JA, Van de Ven WJ. Expression of reciprocal fusion transcripts of the HMGIC and LPP genes in parosteal lipoma. Cancer Genet Cytogenet 1998;106(1):1823. http://dx.doi.org/10.1016/S0165-4608(98)00038-7

26. Panagopoulos I, Gorunova L, Bjerkehagen B, et al. The recurrent chromosomal translocation $t(12 ; 18)(q 14 \sim 15 ; q 12 \sim 21)$ causes the fusion gene HMGA2-SETBP1 and HMGA2 expression in lipoma and osteochondrolipoma. Int $\mathrm{J}$ Oncol 2015;47(3):884-90.

http://dx.doi.org/10.3892/ijo.2015.3099 